DeAR SIR,

EGAZ MONIZ'S NOBEL PRIZE

In his review of Szasz's book The Age of Madness (Joumal, September 1975, 127, 297) Dr Sim maintains that Egaz Moniz received the 1949 Nobel Prize for his work on cerebral angiography. Actually it is as Dr Szasz maintains, ie that Egas Moniz received his prize 'for his discovery of the therapeutic value of leucotomy in certain psychoses'.

Professor of Psychiatry and Chairman,

Carro Preres

Department of Psychiatry,

University of Umea,

S-gol 85 Umsai, Sweden

\section{STENGEL PRIZE}

Drar SIR,

I would like to draw the attention of your readers to the award of the Stengel Prize due to be made in July 1976. The prize was established from contributions by colleagues of the late Professor Stengel to mark his retirement from the Chair of Psychiatry at the University of Sheffield.
The prize of $f_{100}$ is to be awarded every three years to any doctor or group of doctors who have worked in the Trent Region (ie geographical area covered by the Regional Health Authority) for a piece of research in a field related to clinical psychiatry and carried out during tenure of an appointment in the Region, whether in hospital, university, general practice or other service. Preference will be given to doctors who have been qualified for not more than eight years. The prize may be shared at the discretion of the assessors.

The entry should consist of two typed copies of the study written in a manner suitable for publication in a scientific journal. The closing date will be 30 June 1976. Any inquiries concerning the suitability of a project, or eligibility of a candidate should be made to the Board of Assessors.

Hon Secretary,

C. P. Seager

Board of Assessors for the Stengel Prize, Department of Psychiatry,

University of Shaffield,

Whiteley Wood Clinic,

Woofindin Road,

Sheffield, Sזo $3 T L$ 